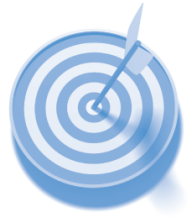

\author{
Elizabeth M Page \\ Department of Chemistry \\ University of Reading \\ Whiteknights Park \\ Reading \\ RG6 6AD
}

e.m.page@reading.ac.uk

David Read

School of Chemistry University of Southampton Highfield

Southampton

SO17 1BJ

d.read@soton.ac.uk

Natalie M Rowley

School of Chemistry University of Birmingham

Edgbaston

Birmingham

B15 TT

n.m.rowley@bham.ac.uk

New and sustainable approaches are needed... in the face of the challenges posed by the new climate in UK Higher Education.

\section{Sowing the seeds of change: students taking the lead in chemical education research projects}

\begin{abstract}
This article outlines the benefits to institutions of engaging students (undergraduate and postgraduate) in carrying out education research projects. The activity outlined herein is probably best described as 'action research', which potentially lays the foundation for chemical education research in the future. These projects aim to identify (or develop) best practice and provide the evidence to convince occasionally cynical academics that a new approach is effective in enhancing learning and/or the student experience. The benefits to the students carrying out the projects in terms of skills development and increased confidence are discussed, along with the benefits to academics and their institutions.
\end{abstract}

\section{Background}

The landscape of UK HE is changing rapidly in the face of numerous new challenges. The introduction of higher tuition fees from 2012 is likely to increase students' expectations, while it is unclear whether or not universities will have adequate resources to deploy in order to meet the resulting new demands. In keeping with many other sectors of the economy, HE will need to deliver 'more for less'. Institutions wills face a multitude of choices with limited resources, and it is essential that waste is avoided by ensuring that changes to provision are based on sound evidence. A key challenge is that this evidence needs to be collected rapidly and at low cost, as the funding available for such research activity is limited.

Chemical education research has had a significant impact on the delivery of teaching in many institutions, with benefits for the student experience ${ }^{1}$. The activities of the HEA's UK Physical Sciences Centre and programmes such as 'Chemistry for our Future' have helped to bring best practices to the attention of teaching staff in a wider range of institutions than ever before, a good example being the dissemination of context- and problem-based learning activities ${ }^{2}$. The ability of academics to carry out such work may diminish as HEFCE cuts lead to the loss of financial support and vital communication links. New and sustainable approaches are needed in order to capitalise on the successes of the work referred to above in the face of the challenges posed by the new climate in UK Higher Education.

\section{Case studies and methodology}

Projects at Birmingham

Fourteen educational projects have been carried out by final year (BSc) students at the University of Birmingham since 2005. These have focussed on the production of web-based resources to support teaching in areas such as spectroscopy, stereochemistry, thermodynamics and kinetics (the latter two areas in conjunction with Dr Sarah Horswell). The students, having recently studied the topics themselves, are well placed to investigate any difficulties which current students encounter when studying a particular area of chemistry. They are also creative in the production of appropriate resources to supplement the undergraduate teaching, and can obtain preliminary feedback from students on the resources created. Indeed some of the students' work helped to support NMR's successful application for a University of Birmingham Teaching Fellowship in 2006.

The success of the undergraduate research projects also paved the way for the School's first MPhil in Chemical Education. The student carried out an undergraduate research project and then undertook a Masters degree examining the experiences of first year chemistry students learning spectroscopy by an enquiry-based approach ${ }^{3}$. This Masters degree was successfully completed in 2009 and the work carried out was instrumental in successfully embedding aspects of enquiry-based learning into the School's undergraduate curriculum. 


\section{Projects at Reading}

Education projects have been offered for several years, but until recently these were mainly coordinated through the Undergraduate Ambassadors' Scheme ${ }^{4}$. Such projects have been highly successful and have attracted very able students, some considering teaching as a career and others who have had their fill of undergraduate lab classes and are looking for an alternative type of project.

One recent project looked into the content and efficacy of Access courses as a preparation for higher education. The project was carried out by a mature student who entered $\mathrm{HE}$ through the Access route herself and had struggled to fill the vast gaps in knowledge between her prior experience and the first year chemistry course. Her findings have been eye-opening and have confirmed the apprehensions most Admissions Tutors have about making offers to applicants with Access qualifications. In the project the student looked at overall success rates in different HE courses, including the physical sciences, of students entering with Access qualifications. The Department has changed its admissions literature regarding Access courses as a result of the findings.

\section{...education projects should not be seen as a 'dumping ground' for less able students, or those who don't perform well in the teaching laboratory.}

Education projects are becoming a mainstream choice at Reading as colleagues in the Department's recently formed Chemical Education Group become more confident in supervising and assessing them.

\section{Projects at Southampton}

Educational projects had been under discussion at Southampton for a number of years so that more choice could be offered to final year students at a time when student numbers had increased significantly. The first student to undertake such a project was an individual who put themselves forward for the role, having being a vociferous contributor to the evaluation of teaching innovations that had been implemented in previous years. The outcomes of this student's project on 'Lecture Capture' were published in $2010,{ }^{5}$ and have been the subject of numerous presentations, several by invitation ${ }^{6}$. The student involved is currently undertaking a Masters in Chemical Education Research, and will shortly begin a $\mathrm{PhD}$ in this field.
This success gave us the confidence to offer projects in 'Education and Outreach' alongside those in our other research areas for the 2010/11 academic year, which led to the recruitment of 9 final year BSc project students. Although a number of these students have worked on outreach or school-level education research projects which are beyond the remit of this article, some have focussed on education research related to our own delivery, an example being research into the effectiveness of sharing learning outcomes with students at $\mathrm{HE}$ level ${ }^{7}$. The high profile of the work undertaken in this period has increased the demand for such projects among students in subsequent year groups.

The benefits and the pitfalls of education-based projects Academic colleagues who have limited experience of chemical education research don't always appreciate the value of such work, which has a number of consequences for those involved in educational development. A key factor is the reluctance of many staff to accommodate change that isn't perceived to be based on solid evidence. Successful research projects can actually provide evidence that has a transformational impact, as in the case of the 'Lecture Capture' project at Southampton which has led to the majority of first year lectures being recorded in the 2010/11 academic year.

Many students decide at an early stage in their degree that a career in a research laboratory is not for them. While many of these students relish the opportunity to test themselves in the lab as part of a research project, others would prefer to turn their hand to a project in an educational context. Such a project may allow them to develop the skills required for a particular career (e.g. teaching), or to develop other specific interests. Of course, it is vital that these students are reminded that this may be their only opportunity to carry out lab-based research, and they should make this decision only after careful consideration. New graduates typically face interview questions about their final year project, particularly when applying for science-based jobs, and a lack of lab experience may be a hindrance to some. However, one education project graduate commented that during her interview for the British Transport Police the panel could understand far more about her project than they would have about any chemistry-based research. She attributes the skills she developed in her project and the opportunity to talk about the work to her success in securing the position.

Many chemistry departments have experienced a significant increase in numbers in recent years, making it more difficult to accommodate project students in research labs. As such, it is challenging to provide comprehensive supervision, which can impact upon the student experience as well as creating safety concerns. By offering an alternative to those students who would like to do something different, it is possible to alleviate those pressures a little. A key caveat is that education projects should not be seen as a 'dumping ground' for less able students, or those who don't perform well in the teaching laboratory. Research in education is more closely related to social science and requires a particular approach and a degree of dedication. As such, unmotivated students or those without the appropriate skills set are unlikely to generate positive outcomes, and can potentially do more harm than good. 
Many departments have academic staff or teaching specialists with an interest in education research, and these may be the ideal supervisors for such project students. They may already have a sense of the requirements of this sort of work, and a team of project students can assist them in achieving career objectives that would otherwise be out of reach. Funding for such work is scarce and undergraduate project students may be the only individuals available to do the 'legwork' required to collect and verify the evidence that underpins any piece of research. In cases where supervisors have no background in education research, it is essential that they are supported by colleagues who do, with particular attention paid to marking criteria and moderation.

Projects based in education can be all too readily dismissed by some of the more 'traditional' members of academic staff who view the final year project more as a rite of passage than a preparation for real-life problem solving. Although educational research is more closely aligned to social science research rather than laboratory-based research the scientific method is still at the heart of the investigation. Education projects are designed in exactly the same way as scientific research projects starting with a hypothesis, followed by a plan of attack. An appropriate method for collecting results is designed and the results subsequently analysed. From this an evaluation of the method is made and conclusions drawn. Written reports of projects follow similar structures independent of the nature of the research and the lab note book can be replaced by a log book of activities, literature searches, records of results etc. In fact mark schemes are fairly transferable from one type of project to another, and it is quite feasible that academics without any prior experience of chemical education research could provide adequate supervision of such students.

\section{Conclusions}

The evidence shows that it is possible for students to undertake research projects in the area of chemical education at $\mathrm{HE}$ level that are successful and have a long-term positive impact on the student experience and the delivery of teaching. The outcomes arising from such projects will be of great value as students begin to demand more from their university teachers in return for their increased fees. Although the 'mind-set' required to carry out educational research is quite different from that needed in the chemistry lab, there is enough support available in the literature for any interested and dedicated academic to turn their hand to such research. As well as relieving pressure on space in research laboratories, educational projects allow students to develop a different range of transferable skills when compared with laboratory-based projects. This is particularly valuable in an era when undergraduates are keen to maximise their skills development during their studies ${ }^{8}$.

\section{References}

1. (a) Johnstone, A. H. (2006) Chemical education research in Glasgow in perspective, Chemistry Education Research and Practice, 7, 49-63.

(b) De Jong, O. (2005) Research and Teaching Practice in Chemical Education: Living apart or together?, Chemical Education International, 6, 2005. This article can be found at: <old.iupac.org/publications/cei/vol6/10_De_Jong.pdf> (accessed on $30^{\text {th }}$ April 2011).

2. Overton, T. L., Byers, B. and Seery, M. K. (2009) Context - and Problem-based Learning in Higher Level Chemistry Education, in Innovative Methods in Teaching and Learning Chemistry in Higher Education, I. Eilks and B. Byers (Eds.), Royal Society of Chemistry.

3. (a) Lucas, T and Rowley, N. M. (2008) Preliminary Findings of Using Enquiry-Based Learning in Chemistry, Proceedings of Variety in Chemistry Education, Overton, T. L. (Ed.), Royal Society of Chemistry, p15.

(b) Rowley, N. M., Lucas, T., McLinden, M. T. and Overton, T. L (2008) Preliminary Findings of Using Enquiry-Based Learning in First Year Undergraduate Chemistry, Birmingham Education, Theory and Action, 1, 9-16

4. Page, E. M. and Almond, M. J. (2008) The Ambassadors, Education in Chemistry, 45, 179-181.

5. Andrews, C. J., Brown, R. C., Harrison, C. K., Read, D. and Roach, P. L. (2010) Lecture capture: Early lessons learned and experiences shared, New Directions in the Teaching of Physical Sciences, 6, 56-60.

6. Read, D. and Harrison, C. K. (2010) Lectures on demand: The student perspective, Proceedings of Variety in Chemistry Education, Overton, T. L. (Ed.), Royal Society of Chemistry, p11. See also: $<$ www.gees.ac.uk/events/2011/earthsci11/ earthsci11.htm> (accessed on April 30th 2011).

7. Boniface, J., Read, D. and Russell, A. E. (2011) Sharing learning outcomes in Chemistry teaching at HE level: beneficial or detrimental?, New Directions in the Teaching of Physical Sciences, 7, 31-35.

8. Hanson, S. W. and Overton, T. L. (2010) Skills required by new chemistry graduates and their development in degree programmes, Higher Education Academy UK Physical Sciences Centre. 